\title{
Fecal bile acid excretion and messenger RNA expression levels of ileal transporters in high risk gallstone patients
} Jorge Herrera1 ${ }^{1}$, Ludwig Amigo ${ }^{1}$, Constanze Husche ${ }^{2}$, Carlos Benítez ${ }^{1}$, Silvana Zanlungo ${ }^{1}$, Dieter Lütjohann² ${ }^{2}$ Juan Francisco Miquel ${ }^{1}$ and Flavio Nervi*1

Address: ${ }^{1}$ Departamento de Gastroenterología, Facultad de Medicina, Pontificia Universidad Católica de Chile, Santiago, Chile and ${ }^{2}$ Labor für spezielle Lipiddiagnostik, Zentrum Innere Medizin, Institut für Klinische Chemie und Pharmakologie, Universitätsklinikum Bonn, Germany

Email: Jorge Herrera - jgherrer@gmail.com; Ludwig Amigo - ludwig@med.puc.cl; Constanze Husche - Constanze.Husche@ukb.uni-bonn.de; Carlos Benítez - benitezc@gmail.com; Silvana Zanlungo - silvana@med.puc.cl; Dieter Lütjohann - Dieter.Luetjohann@ukb.uni-bonn.de; Juan Francisco Miquel - jfmiquel@med.puc.cl; Flavio Nervi* - fnervi@med.puc.cl

* Corresponding author

Published: 8 December 2009

Lipids in Health and Disease 2009, 8:53 doi:10.1I86/1476-5IIX-8-53

This article is available from: http://www.lipidworld.com/content/8/I/53

(c) 2009 Herrera et al; licensee BioMed Central Ltd.

This is an Open Access article distributed under the terms of the Creative Commons Attribution License (http://creativecommons.org/licenses/by/2.0), which permits unrestricted use, distribution, and reproduction in any medium, provided the original work is properly cited.
Received: 14 September 2009

Accepted: 8 December 2009

\begin{abstract}
Background: Cholesterol gallstone disease (GS) is highly prevalent among Hispanics and American Indians. In GS, the pool of bile acids (BA) is decreased, suggesting that BA absorption is impaired. In Caucasian GS patients, mRNA levels for ileal BA transporters are decreased. We aimed to determine fecal BA excretion rates, mRNA levels for ileal BA transporter genes and of regulatory genes of BA synthesis in Hispanic GS patients.
\end{abstract}

Results: Excretion of fecal BA was measured in seven GS females and in ten GS-free individuals, all with a body mass index $<29$. Participants ingested the stool marker $\mathrm{Cr}_{2} \mathrm{O}_{3}(300 \mathrm{mg} / \mathrm{day})$ for 10 days, and fecal specimens were collected on the last 3 days. Chromium was measured by a colorimetric method, and BA was quantitated by gas chromatography/mass spectroscopy. Intake of calories, nutrients, fiber and cholesterol were similar in the GS and GS-free subjects. Mean BA excretion levels were $520 \pm 80 \mathrm{mg} /$ day for the GS-free group, and $46 \mathrm{I} \pm 105 \mathrm{mg} / \mathrm{day}$ for the GS group. Messenger RNA expression levels were determined by RT-PCR on biopsy samples obtained from ileum during diagnostic colonoscopy (I4 GS-free controls and 16 GS patients) and from liver during surgery performed at 8 and 10 AM (I2 GS and 10 GS-free patients operated on for gastrointestinal malignancies), all with a body mass index $<29$. Messenger RNA level of the BA transporter genes for ileal lipid binding protein, multidrug resistance-associated protein 3, organic solute transporter alpha, and organic solute transporter beta were similar in GS and GS-free subjects. Messenger RNA level of Cyp27AI, encoding the enzyme $27 \alpha$-hydroxylase, the short heterodimer partner and farnesoid $X$ receptor remained unchanged, whereas the mRNA level of Cyp7AI, the rate limiting step of BA synthesis, was increased more than $400 \%(p<0.01)$ in the liver of GS compared to GS-free subjects.

Conclusion: Hispanics with GS have fecal BA excretion rates and mRNA levels of genes for ileal BA transporters that are similar to GS-free subjects. However, mRNA expression levels of Cyp7AI are increased in GS, indicating that regulation of BA synthesis is abnormal in Hispanics with GS. 


\section{Background}

Cholesterol gallstone disease (GS) is prevalent worldwide, and is endemic among American Indians and Hispanics $[1,2]$. In GS, the primary abnormality is secretion by the liver into the gallbladder of bile that is supersaturated with cholesterol. This leads to precipitation of cholesterol and formation of gallstones. The most common causes of cholesterol-saturated bile are a decrease in the bile acid (BA) pool and secretion rate and an increase in cholesterol output into the bile $[3,4]$. Thus, one current hypothesis about the primary cause of GS is abnormal regulation of cholesterol and BA metabolism.

Fecal BA excretion rate is a marker of daily BA synthesis, and is higher in Argentinean Hispanic patients with GS than in GS-free individuals [5]. Similarly, BA synthesis, indirectly assessed by the measurement of serum $7 \alpha$ hydroxy-4-cholesten-3-one concentration in one point in time, was found increased in Chilean Hispanics with GS compared to GS-free individuals, suggesting increase BA synthesis in GS $[6,7]$. Similar results were observed in Caucasian individuals $[8,9]$. Consistent with these findings, the mRNA levels of BA transporter genes are decreased in the ileum of female Caucasian GS patients, supporting the hypothesis that absorption of $\mathrm{BA}$ is impaired and fecal BA excretion is increased in subsets of GS patients [10,11]. GS-free North American Indians, a population with an extremely high prevalence of GS, also have higher fecal BA excretion rates than non-Indian subjects [12]. However, GS patients who are North American Indians [12] or obese non-Indians [13] have fecal BA excretion levels that are similar compared to levels found in GS-free subjects. Consistent with these findings, other studies performed among Italian [14] and Chinese [15] subjects have shown unchanged mRNA expression levels of CYP7A1, the ratelimiting enzyme of BA synthesis.

These apparent discrepancies might be because the mechanisms of GS formation are different in patients with different ethnic backgrounds, or because indirect assessment of BA synthesis in one part of the day might not reflect total daily production of $\mathrm{BA}$, as occurs with the measurement of daily fecal BA excretion. Thus, the objective of this study was to quantitate daily fecal BA excretion rates, mRNA expression levels of ileal BA transporters and of hepatic regulatory genes of BA synthesis, in GS patients from a high-risk Hispanic population.

\section{Results}

Nutrients and caloric intake were similar in GS-free control subjects and GS patients in this study of fecal BA excretion (results not shown). Caloric intake varied from 1220 to $2237 \mathrm{Kcals} /$ day for all subjects. Fiber intake varied between 19.3 and $24.1 \mathrm{~g} /$ day, and cholesterol intake varied between 94.4 and $281.3 \mathrm{mg} / \mathrm{day}$, and both were simi- lar in GS-free and GS patients. All subjects were non-obese and had similar values for age, body mass index (BMI) and serum lipids (Table 1). No significant differences were observed in daily fecal BA excretion rates between the GS-free and GS patient groups, with rates varying from $186 \pm 53$ (mean \pm standard error) and $883 \pm 53 \mathrm{mg} /$ day in the GS-free patients, and from $120 \pm 17$ and $897 \pm 157$ $\mathrm{mg} /$ day in the GS group (Table 1 ).

The mRNA levels of genes involved in the regulation of the enterohepatic circulation of BA in the ileum were analyzed in GS and GS-free subjects with similar average ages and BMIs. Histological analysis of ileal biopsies showed no abnormalities for either GS-free or GS patients. As shown in Table 2, no differences were observed between GS patients and GS-free subjects in the mRNA levels of BA transporter genes, including the apical sodium dependent bile acid transporter (Astb); Fabp6, which is the gene for ileal lipid binding protein (ILBP); $A b c c 3$, which is the gene for multidrug resistance-associated protein 3 (MRP3); or Ost and Ost, which are the genes for the organic solute transporters alpha and beta. Similarly, no changes were seen in the expression levels of FGF19, the ileal hormone that regulates BA synthesis.

The mRNA levels of regulatory genes of BA synthesis were determined in liver biopsies obtained from a series of GS and GS-free subjects subjected to laparotomy for GS, or for localized gastrointestinal malignancies, respectively. Histological analysis of liver biopsies was normal for either GS-free or GS patients. As shown in Table 3, the mRNA level of Cyp7A1, the gene encoding $7 \alpha$-hydroxylase, the rate limiting step of BA synthesis, was increased by $>400 \%(\mathrm{p}<0.01)$ in GS compared to GS-free patients. No differences were observed between GS patients and GS-free subjects in the mRNA levels of Cyp27A1 and of regulatory genes of BA synthesis, including NrOB2 (short heterodimer partner) and $\mathrm{Nr} 1 \mathrm{H} 4$ (farnesoid X receptor, FXR).

\section{Discussion}

This study found similar rates of daily BA excretion in the feces of Chilean Hispanic GS patients and GS-free individuals. Our observations do not support the results of Mamianetti et al., who found increased BA excretion levels in the feces of GS patients compared to GS-free subjects [5]. However, since that study was performed without a fecal marker to correct for fecal flow, its findings are difficult to interpret, and cannot be compared to our study and other similar studies in which fecal flow markers were used to assess sterol excretion and balance [16-18]. Other studies that have reported fecal BA excretion rates in GS patients show similar daily rates of BA excretion in the feces of GS and GS-free subjects $[12,13]$. 
Table I: Age, BMI, serum lipids and fecal BA excretion in control and GS patients.

\begin{tabular}{|c|c|c|c|c|c|c|}
\hline \multirow[b]{2}{*}{ Subjects } & \multicolumn{6}{|c|}{ Serum lipid concentration $(\mathrm{mg} / \mathrm{dl})$} \\
\hline & Age (y) & BMI & Total CH & HDL & TG & Fecal BA (mg/day) \\
\hline \multicolumn{7}{|l|}{ GS-free } \\
\hline 1 & 48 & 23.4 & 170 & 52 & 99 & $883 \pm 53$ \\
\hline 2 & 43 & 23.4 & 223 & 46 & 73 & $824 \pm 68$ \\
\hline 3 & 46 & 22.2 & 219 & 59 & 220 & $418 \pm 140$ \\
\hline 4 & 36 & 23.7 & 219 & 67 & 57 & $880 \pm 150$ \\
\hline 5 & 22 & 28.3 & 194 & 58 & 81 & $250 \pm 54$ \\
\hline 6 & 48 & 22.1 & 226 & 76 & 68 & $428 \pm 140$ \\
\hline 7 & 34 & 22.4 & 153 & 60 & 38 & $420 \pm 127$ \\
\hline 8 & 36 & 26.3 & 192 & 50 & 100 & $403 \pm 140$ \\
\hline 9 & 37 & 24.1 & 158 & 37 & 111 & $186 \pm 30$ \\
\hline 10 & 55 & 23.0 & 247 & 66 & 104 & $508 \pm 250$ \\
\hline Mean \pm SE & $41 \pm 3$ & $24.1 \pm 0.6$ & $198 \pm 10$ & $57 \pm 4$ & $95 \pm 16$ & $520 \pm 80$ \\
\hline \multicolumn{7}{|c|}{ With gallstones } \\
\hline 11 & 55 & 23.8 & 247 & 66 & 104 & $374 \pm 9$ \\
\hline 12 & 51 & 22.5 & 163 & 50 & 65 & $576 \pm 250$ \\
\hline 13 & 30 & 22.5 & 150 & 39 & 165 & $314 \pm 86$ \\
\hline \multicolumn{7}{|c|}{ Cholecystectomy } \\
\hline 14 & 47 & 22.1 & 150 & 28 & 177 & $324 \pm 46$ \\
\hline 15 & 53 & 22.0 & 148 & 50 & 118 & $120 \pm 17$ \\
\hline 16 & 37 & 24.1 & 162 & 44 & 146 & $897 \pm 157$ \\
\hline 17 & 30 & 26.7 & 150 & 39 & 165 & $538 \pm 170$ \\
\hline \multicolumn{7}{|l|}{ Total GS } \\
\hline Mean \pm SE & $47 \pm 4$ & $23.4 \pm 0.6$ & $158 \pm 3$ & $46 \pm 4$ & $114 \pm 19$ & $46 I \pm 105$ \\
\hline
\end{tabular}

Each individual value of fecal BA excretion represents the mean \pm SE of the three days of fecal collection of each participant. Body weights were: GS-free subjects, $58.6 \pm$ I.9; GS patients, $55.3 \pm$ I.7. BMI was calculated as weight/height $\left(\mathrm{kg} / \mathrm{m}^{2}\right)$; $\mathrm{CH}$, cholesterol; $\mathrm{TG}$, triglycerides.

Consistent with the apparently normal daily fecal BA excretion in GS patients, we found that GS-free and GS patients had similar mRNA levels for BA transporter genes in the ileum. This observation suggested that this group of GS patients had no abnormalities in ileal BA absorption, in contrast with the decreased mRNA levels of BA trans-

Table 2: Expression levels of mRNA of ileal transporters of BA and FGFI 9 in GS patients.

\begin{tabular}{lrll}
\hline Gene symbol & Gene ID & Expression value in GS & P value \\
\hline Slc10A2 & 6555 & $0.99 \pm 0.19$ & 0.964 \\
Fabp6 & 2172 & $1.01 \pm 0.11$ & 0.983 \\
Abcc3 & 8714 & $1.08 \pm 0.07$ & 0.586 \\
Ost & 200931 & $1.18 \pm 0.11$ & 0.425 \\
Ost & 123264 & $1.02 \pm 0.08$ & 0.902 \\
Fgf19 & 9965 & $1.30 \pm 0.20$ & 0.411 \\
\hline
\end{tabular}

Expression represent the mean values $\pm \mathrm{SE}$ of GS subjects. Expression values for GS-free subjects were assigned as 1.00. Participants of the study were: GS, $\mathrm{n}=16(16 \mathrm{GS}, 12 \mathrm{~F} / 4 \mathrm{M}$ and 7$)$, GS-free subjects, $\mathrm{n}=$ 14 (8 F/6 M). Age ranges were $62 \pm 2$ for GS-free, $57 \pm 3$ for GS. Gene ID corresponds to gene annotation obtained from NCBI web site. Expression of the following genes were determined: SICIOA2, ASBT (Apical sodium dependent bile acid transporter); Fabp6, ILBP (lleal Lipid Binding protein); Abcc3, MRP3 (Multidrug resistanceassociated protein 3); Ost , Organic solute transporter alpha; Ost , Organic solute transporter beta; Fg/ I9, Fibroblast growth factor 19. porters observed in the ileum of Caucasian female GS patients in other studies $[10,11]$. Our results indicate that Chilean Hispanics with GS maintain a normal rate of BA absorption in the ileum. However, a specific abnormality in the expression levels of ileal BA transporters in GS patients may not be detected in this population because of

Table 3: mRNA expression levels of hepatic regulatory genes of BA synthesis in GS patients.

\begin{tabular}{lrlc}
\hline Gene symbol & Gene ID & Expression value \pm SE & p value \\
\hline Cyp7AI & $158 I$ & $4.12 \pm 2.68$ & $0.012^{*}$ \\
Cyp27AI & 1593 & $1.10 \pm 0.45$ & 0.717 \\
NrOB2 & 604630 & $1.08 \pm 0.52$ & 0.788 \\
NrIH4 & 603826 & $0.83 \pm 0.28$ & 0.523 \\
\hline
\end{tabular}

Expression values represent the mean $\pm \mathrm{SE}$ of GS subjects. Expression values for GS-free subjects were assigned as 1.00. Participants of the study were: GS, $n=12(9 \mathrm{~F} / 3 \mathrm{M})$, GS-free subjects, $n=10(5 \mathrm{~F} / 5 \mathrm{M})$. Age ranges were $50 \pm 4$ for GS and $56 \pm 5$ for GS-free. Gene ID corresponds to gene annotation obtained from NCBI. Cyp7AI, cytochrome $\mathrm{P} 450$, family 7 , subfamily $\mathrm{A}$, polypeptide I (cholesterol $7 \alpha$-hydroxylase); Cyp27AI, cytochrome P450, family 27, subfamily A, polypeptide I (sterol $27 \alpha$-hydroxylase); NrOB2 nuclear receptor subfamily 0 , group B, member 2 (short heterodimer partner); $\mathrm{Nr} / \mathrm{H} 4$, Nuclear receptor subfamily 0 , group $H$, member 4 (farnesoid $x$ receptor, FXR). 
the extremely high prevalence of GS among Chileans, who were used as both patients and controls in this study.

The finding that fecal BA excretion is unchanged in our GS patients is consistent with normal rates of daily BA synthesis determined by isotopic methods in GS $[19,20]$ and with normal mRNA expression levels of CYP7A1 found among Italian [14] and Chinese [15] GS patients. These observations apparently contradicts the finding of increased mRNA levels of CYP7A1 of the present study and the previously reported increase in $7 \alpha$-hydroxy- 4 cholesten-3-one in serum in Hispanics [6,7], as well as in Caucasian GS patients $[8,9]$. The most likely explanation for this apparent contradiction is that the increased CYP7A1 mRNA and serum $7 \alpha$-hydroxy-4-cholesten-3-one concentration seen in GS patients was observed at a single time point, measured by an indirect assessment of BA synthesis. Thus, the values may not reflect the daily rate of $\mathrm{BA}$ synthesis as measured by the daily fecal BA excretion method, or by isotopic methods. BA synthesis shows a rapidly changing circadian rhythm in rodents [21] and in humans [22]. Therefore, the increase in BA synthesis, assessed by either CYP7A1 mRNA, or a serum marker of BA synthesis measured at only one point during the day, may indicate a secondary phenomenon that is an effect of the loss of gallbladder function in some populations, and not a primary pathogenic defect of all GS patients. Whether the mechanism responsible for the increase mRNA expression levels of CYP7A1 in GS is mediated by the FXR nuclear receptor - dependent or FGF 19 - dependent mechanism, cannot be elucidated with the results obtained in these studies. It is possible that the fraction of the BA pool stored in the intestine during the night is higher in GS patients compared to GS-free subjects. This situation could decrease BA concentration in hepatocytes and consequently, decrease FXR activity followed by increase of mRNA levels of CYP7A1 early in morning, when liver biopsies and serum samples are obtained from the subjects participating in these studies. Alternatively, loss of gallbladder function because of the presence of gallstones, or cholecystectomy could change the daily secretion pattern of FGF19 with the subsequent modification of the circadian rhythm of CYP7A1 mRNA.

The fecal BA excretion rates previously reported for North American Indians are higher than rates observed for Caucasian individuals $[12,16-18]$, but similar to the values reported here. This suggests that Amerindians may have higher rates of fecal BA excretion than other populations, which might represent a common ethnic predisposition to form gallstones, resulting from a reduced capacity for BA absorption in the ileum. Another possibility relates to the presence of common dietary constituents in the diet of Amerindians and Hispanics that might increase fecal BA excretion and cholesterol saturation in bile such as occurs with legume diets $[18,23]$, a common foodstuff in these populations $[23,24]$. Specific types of fiber, such as the saponin component in the soluble fraction of legumes, may increase the synthesis of BA $[25,26]$ and favour its excretion in feces [18]. Interestingly, the levels of fecal BA excretion reported here in GS patients and GS-free subjects were similar to values reported for Caucasian subjects ingesting a diet high in fiber [16] or in legumes [18].

\section{Conclusion}

Fecal BA excretion, a marker of daily BA synthesis, and mRNA expression levels of ileal transporters remain unchanged in GS compared to GS-free Hispanic subjects. Increased CYP7A1 mRNA expression levels found in GS compared to GS-free subjects, suggests that regulation of BA synthesis is abnormal in GS patients from Hispanic populations.

\section{Methods \\ Patient selection and sample collection}

The Institutional Review Board for Human Studies of the Faculty of Medicine at the Pontificia Universidad Católica de Chile approved this study, which was conducted according to the 1975 Declaration of Helsinki. All subjects participating in this study gave informed consent.

Daily excretion of fecal BA was measured in seven GS female patients (3 with gallstones and 4 cholecystectomized), and in 10 GS-free female subjects. All participants worked at our institution as nurse assistants. Gallstone disease was defined as either asymptomatic cholelithiasis previously diagnosed by ultrasound, or antecedent of cholecystectomy performed $>2$ years prior to the study. GS are mainly of the cholesterol type in the Chilean population [2] and the morphology of patients's gallstones was of the cholesterol type in this study [27]. Criteria for selection included: a) normal weight (BMI $<29)$; b) normal serum glucose, insulin and albumin concentrations; c) no antecedent of obesity or known changes of $>5 \%$ in habitual body weight for 6 months prior to the study; d) no antecedent of inflammatory bowel disease, or diarrhea for 2 months prior to the study; d) no antecedent of treatment with drugs affecting lipid metabolism. As a stool marker of fecal flow, each subject ingested a capsule containing $100 \mathrm{mg} \mathrm{Cr}_{2} \mathrm{O}_{3}$ (Merck, Darmstadt, Germany), with the main meals, three times daily for ten days. Daily fecal specimens were obtained for the last 3 days of the study protocol, and stored at $-20^{\circ} \mathrm{C}$ until processing. Subjects ingested two daily meals at the Pontificia Universidad Católica de Chile. Dietary energy, cholesterol, fat, carbohydrate, protein and fiber were calculated from 7 day dietary records using the software Food Processor 7.9 (ESHA Research, Oregon, USA). 
The experimental protocols of the ileal and liver biopsy studies included subjects that had a BMI $<29$, normal serum glucose, and no antecedent of treatment with drugs affecting lipid metabolism, including thyroid hormones, or drugs for treatment of inflammatory bowel disease. The ileal biopsy study included 14 GS-free controls ( 8 female, 6 male), 16 GS subjects (9 with gallstones, 7 females, 2 males and 7 cholecystectomized, 5 females, 2 males), all undergoing diagnostic colonoscopy for screening purposes. Cholecystectomized patients had cholecystectomy performed at least 3 years prior to colonoscopy. For each patient, five to seven ileal biopsy specimens were obtained from approximately $10 \mathrm{~cm}$ proximal to the ileocecal valve in the ileal biopsy study. The experimental protocol for the liver biopsy study included 12 GS patients (9 female, 3 male), subjected to elective surgery because of previously symptomatic GS and a control group formed by 10 GS-free individuals ( 5 female, 5 male), operated upon because of gastrointestinal cancer localized to the affected organ. A liver biopsy was obtained at the beginning of the surgical procedure.

A specimen of both the ileal and liver biopsy studies from each individual were fixed and stained with hematoxylineosin for histological analysis. All non-GS patients had a normal abdominal ultrasound for assessment of GS.

\section{Determination of fecal BA excretion}

Fecal samples from three days of collection were subjected to alkaline hydrolysis according to de Wael et al. [28]. Unconjugated BA was extracted into diethyl ether and quantitated by gas chromatography/mass spectroscopy as previously described [29,30]. Fecal chromium from the ingested chromium oxide $\left(\mathrm{Cr}_{2} \mathrm{O}_{3}\right)$ was determined according to Calvert et al. [31]. Concentrations of chromium and acidic sterols in feces 13 were calculated per gram of fecal homogenate. The daily excretion of BA was determined by the equation:

BA (mg / day) = acidic sterols (mg/g sample) $\times \mathrm{Cr}$ (mg/day) / Cr (mg/g sample)

RNA extraction, reverse transcription and real-time PCR analysis

Total RNA was isolated from ileal biopsies by an acidic guanidinium isothiocyanate/phenol/chloroform extraction procedure, as described by Chomczynski and Sacchi [32]. Total RNA was reverse transcribed using the SuperScript First-Strand Synthesis System for RT-PCR (Invitrogen, Bios Chile, I.G.S.A., Santiago, Chile) and random hexamers. Quantitative polymerase chain reaction (PCR) was performed in a Mx3000P Real-Time PCR System (Stratagene, La Jolla, CA, USA) using Platinum Quantitative PCR SuperMix-UDG (Invitrogen, Bios Chile, I.G.S.A., Santiago, Chile), and 25 ng of reverse transcribed RNA. Specific TaqMan Gene Expression Assays (Applied Biosystems, Foster City, CA) were performed for genes that reg- ulate BA synthesis in the liver and BA absorption in the ileum, and for eukaryotic 18S rRNA. The primers used in the study are the following references from Applied Biosystems: Slc10A2, Hs00166561_m1; Fabp6, ILBP, Hs00155029_m1; Abcc3， Hs 00358656_m1; Ost， Hs00380895_m1; Ost, Hs00418306_m1; Fgf19, Hs00391591_m1; Cyp7A1，Hs 00167982_m1; Cyp27A1; Hs00168003_m1; NrOB2, Hs00222677_m1; Nr1H4, Hs00231968_m 1 . Thermal cycling conditions were $95^{\circ} \mathrm{C}$ for 10 minutes followed by 40 cycles at $93^{\circ} \mathrm{C}$ for $15 \mathrm{sec}-$ onds, and $60^{\circ} \mathrm{C}$ for 1 minute. Reactions were performed in duplicate. Relative quantification of gene expression was performed using the comparative threshold (Ct) method as described by Applied Biosystems (Foster City, CA, USA). Changes in mRNA expression level were calculated following normalization to $18 \mathrm{~S}$ expression (Applied Biosystems reference: Hs99999901_s1).

\section{Statistics}

Data are presented as mean \pm standard error of the mean. Statistical analysis was carried out by Student's $t$-test. The Ct value obtained for control and GS samples was submitted to a $t$-student analysis using REST-MCS software [33]. Differences were considered significant when $\mathrm{p}<0.05$.

\section{List of abbreviations}

BA: bile acids; BMI: body mass index; (CYP7A1): cholesterol $7 \alpha$-hydroxylase; GS: gallstone disease; (RT-PCR): real-time reverse transcription-polymerase chain reaction.

\section{Competing interests}

The authors declare that they have no competing interests.

\section{Authors' contributions}

$\mathrm{JH}, \mathrm{CH}$, LA and $\mathrm{CB}$ performed the majority of experiments; SZ, DL, JFM provided analytical tools and reagents and were involved in editing the manuscript; FN designed the study, co-ordinated and provided the collection of human material, wrote the manuscript, and provided financial support for this work. All authors read and approved the final manuscript.

\section{Acknowledgements}

This study was supported by FONDECYT Grants N 107089I, 1070622 1080325.

\section{References}

I. Shaffer EA: Gallstone disease: Epidemiology of gallbladder stone disease. Best Pract Res Clin Gastroenterol 2006, 20:98I-996.

2. Miquel JF, Covarrubias C, Villaroel L, Mingrone G, Greco AV, Puglielli L, Carvallo P, Marshall G, Del Pino G, Nervi F: Genetic epidemiology of cholesterol cholelithiasis among Chilean Hispanics, Amerindians, and Maoris. Gastroenterology 1998, I 1 5:937-946.

3. Zanlungo S, Rigotti A: Determinants of transhepatic cholesterol flux and their relevance for gallstone formation. Liver Int 2009, 29:323-330.

4. Portincasa P, Moschetta A, Palasciano G: Cholesterol gallstone disease. Lancet 2006, 368:230-239. 
5. Mamianetti A, Garrido D, Carducci CN, Vescina MC: Fecal bile acid excretion profile in gallstone patients. Medicina (B Aires) 1999, 59:269-273.

6. Gälman C, Miquel JF, Pérez R, Einarsson C, Ståhle L, Marshall G, Nervi $F$, Rudling M: Bile acid synthesis is increased in Chilean Hispanics with gallstones and in gallstone high-risk Mapuche Indians. Gastroenterology 2004, 1 26:74|-748.

7. Castro J, Amigo L, Miquel JF, Gälman C, Crovari F, Raddatz A, Zanlungo S, Jalil R, Rudling M, Nervi F: Increased activity of hepatic microsomal triglyceride transfer protein and bile acid synthesis in gallstone disease. Hepatology 2007, 45: I26I-I 266.

8. Muhrbeck O, Wang FH, Björkhem I, Axelson M, Einarsson K: Circulating markers for biosynthesis of cholesterol and bile acids are not depressed in asymptomatic gallstone subjects. J Hepatol 1997, 27: I50-155.

9. Sauter G, Berr F, Beuers U, Fischer S, Paumgartner G: Serum concentrations of 7alpha-hydroxy-4-cholesten-3-one reflect bile acid synthesis in humans. Hepatology 1996, 24:123-126.

10. Bergheim I, Harsch S, Mueller O, Schimmel S, Fritz P, Stange EF: Apical sodium bile acid transporter and ileal lipid binding protein in gallstone carriers. J Lipid Res 2006, 47:42-50.

II. Renner O, Harsch S, Strohmeyer A, Schimmel S, Stange EF: Reduced ileal expression of OSTalpha - OSTbeta in non-obese gallstone disease. J Lipid Res 2008, 49:2045-2054.

12. Grundy SM, Metzger AL, Adler RD: Mechanisms of lithogenic bile formation in American Indian women with cholesterol gallstones. J Clin Invest 1972, 5 1:3026-3043.

13. Miettinen T: Cholesterol production in obesity. Circulation 1971, 44:842-850.

14. Bertolotti M, Gabbi C, Anzivino C, Mitro N, Godio C, De Fabiani E, Crestani M, Del Puppo M, Ricchi M, Carulli L, Rossi A, Loria P, Carulli $\mathrm{N}$ : Decreased hepatic expression of PPAR-gamma coactivator-I in cholesterol cholelithiasis. Eur J Clin Invest 2006, 36: $170-175$.

15. Jiang ZY, Parini P, Eggertsen G, Davis MA, Hu H, Suo GJ, Zhang SD, Rudel LL, Han TQ, Einarsson C: Increased expression of LXR alpha, ABCG5, ABCG8, and SR-BI in the liver from normolipidemic, nonobese Chinese gallstone patients. I Lipid Res 2008, 49:464-472.

16. Kesäniemi YA, Tarpila S, Miettinen TA: Low vs high dietary fiber and serum, biliary, and fecal lipids in middle-aged men. $\mathrm{Am} J$ Clin Nutr 1990, 5: I007-I I I 2.

17. Czubayko F, Beumers B, Lammsfuss S, Lütjohann D, von Bergmann K: A simplified micro-method for quantification of fecal excretion of neutral and acidic sterols for outpatient studies in humans. J Lipid Res 1991, 32:186I-1867.

18. Duane WC: Effects of legume consumption on serum cholesterol, biliary lipids, and sterol metabolism in humans. J Lipid Res 1997, 38: | I20-II28.

19. Vlahcevic ZR, Bell CC Jr, Buhac I, Farrar JT, Swell L: Diminished bile acid pool size in patients with gallstones. Gastroenterology 1970, 59:165-173.

20. Berr F, Pratschke E, Fischer S, Paumgartner G: Disorders of bile acid metabolism in colesterol gallstone disease. J Clin Invest 1992, 90:859-868.

21. Noshiro M, Nishimoto M, Okuda K: Rat liver cholesterol 7 alphahydroxylase. Pretranslational regulation for circadian rhythm. J Biol Chem 1990, 265:10036-10041.

22. Gälman C, Angelin B, Rudling M: Bile acid synthesis in humans has a rapid diurnal variation that is asynchronous with cholesterol synthesis. Gastroenterology 2005, I 29: | 445 - I 453.

23. Hesse FG: A Dietary Study of the Pima Indian. Amer J Clin Nutr 1059, 7:532-537.

24. Nervi F, Covarrubias C, Bravo P, Velasco N, Ulloa N, Cruz F, Fava M, Severin C, Del Pozo R, Antezana, Valdivieso V, Arteaga A: Influence of legume intake on biliary lipids and cholesterol saturation in young Chilean men. Gastroenterology 1989, 96:825-830.

25. Marzolo MP, Amigo L, Nervi F: Hepatic production of very low density lipoprotein, catabolism of low density lipoprotein, biliary lipid secretion, and bile salt synthesis in rats fed a bean (Phaseolus vulgaris) diet. J Lipid Res 1993, 34:807-8|4.

26. Amigo L, Marzolo MP, Aguilera JM, Hohlberg A, Cortés M, Nervi F: Influence of different dietary constituents of beans (phaseolus vulgaris) on serum and biliary lipids in the rat. J Nutr Biochem 1992, 3:486-490.
27. Lee SP, Kuver R: Gallstones. In Textbook of gastroenterology Volume 2. Edited by: Yamada T, Alpers DH, Owyang C, Powell DW, Silverstein FE. Philadelphia: Lippincott; 1995:2187-2200.

28. De Wael J, Raaymakers CE, Endeman HJ: Simplified quantitative determination of total fecal bile salts. Clin Chim Acta 1977, 79:465-470

29. Lütjohann D, Björkhem I, Beil UF, von Bergmann K: Sterol absorption and sterol balance in phytosterolemia evaluated by deuterium-labeled sterols: effect of sitostanol treatment. J Lipid Res 1995, 36:1763-1773.

30. Sudhop T, Lütjohann D, Kodal A, Igel M, Tribble DL, Shah S, Perevozskaya I, von Bergmann K: Inhibition of intestinal cholesterol absorption by ezetimibe in humans. Circulation 2002, 106:1943-1948.

3I. Calvert RJ, Kritchevsky ES, Einhorn E, Klurfeld OM, Kritchevsky D: An improved method for oxidation of chromium (III) oxidecontaining fecal samples by using sodium peroxide fusion. Am J Clin Nutr 1989, 49:90I-903.

32. Chomczynski P, Sacchi N: Single-Step Method of RNA Isolation by Acid Guanidinium Thiocyanate-Phenol-Chloroform Extraction. Anal Biochem 1987, 162:156-159.

33. Pfaffl MW: A new mathematical model for relative quantification in realtime PCR. Nucleic Acid Research 2003, 29:2002-2007.
Publish with Bio Med Central and every scientist can read your work free of charge

"BioMed Central will be the most significant development for disseminating the results of biomedical research in our lifetime. "

Sir Paul Nurse, Cancer Research UK

Your research papers will be:

- available free of charge to the entire biomedical community

- peer reviewed and published immediately upon acceptance

- cited in PubMed and archived on PubMed Central

- yours - you keep the copyright
BioMedcentral 